\title{
Migration of the Abdominal Catheter of a Ventriculoperitoneal Shunt into the Scrotum
}

\section{-Case Report-}

\author{
M. Faik ÖZVEREN, Ahmet KAZEZ*, Hasan ÇETIN, and Ibrahim M. ZIYAL** \\ Departments of Neurosurgery and *Pediatric Surgery, Firat University, School of Medicine, Elazığ, \\ Turkey; **Department of Neurosurgery, Abant Izzet Baysal University, \\ School of Medicine, Düzce, Turkey
}

\begin{abstract}
A 3-day-old male neonate presented with migration of the ventriculoperitoneal (VP) shunt tip through the patent processus vaginalis resulting in scrotal hydrocele. The association of myelomeningocele with hydrocephalus may have been a predisposing factor in this rare complication. Development of scrotal swelling or hydrocele in a child with VP shunt should be recognized as a possible shunt complication.
\end{abstract}

Key words: hydrocephalus, myelomeningocele, ventriculoperitoneal shunt, processus vaginalis, scrotum

\section{Introduction}

Ventriculoperitoneal (VP) shunt is commonly employed in the management of hydrocephalus. Various complications such as dissection or migration may develop besides shunt malfunction. Migration may occur into the lateral ventricle, ${ }^{\overline{5}, 12]}$ mediastinum, ${ }^{6)}$ gastrointestinal tract, ${ }^{21,23)}$ abdominal wall, ${ }^{22)}$ bladder, ${ }^{10)}$ vagina, ${ }^{15)}$ or scrotum. ${ }^{2,7,8,14,16,17,20)}$

We present a case of migration of the peritoneal catheter into the scrotum of a neonate.

\section{Case Report}

A 3-day-old male neonate was admitted to the Firat University Hospital for treatment of lumbosacral myelomeningocele. Physical examination found sunset sign, distended anterior fontanelle, pes equinovarus deformity, and paraplegia. The base of the sac was $10 \mathrm{~cm}$ in diameter. Cranial computed tomography showed hydrocephalus.

The sac was excised protecting the neural placode and the defect was repaired by bilateral latissimus

Received July 21, 1998; Accepted November 20, 1998 dorsi and gluteus maximus musculocutaneous flaps. A VP shunt device was introduced for the hydrocephalus. We used a Pudenz peritoneal catheter.

Twenty-four hours following the operation, the bilateral scrota were swollen, more prominently on the right. The distal tip of the shunt could be palpated in the right scrotum, and appeared on radiography of the abdomen (Fig. 1) An indirect inguinal hernia repaired and the distal tip replaced into the peritoneum (Fig. 2). A prophylactic operation was performed on the left.

\section{Discussion}

Detachment of a peritoneal catheter may result from disconnection due to a loose ligature or the ligature stitch. ${ }^{373}$ The Raimondi catheter may be more vulnerable to repeated traction than conventional silicone catheters, as several such cases have occurred. ${ }^{7,15,22)}$

Migration of the peritoneal catheter into the scrotum through the unobliterated processus vaginalis has been reported previously, but the tube was not dissected in all cases. ${ }^{2,7,11,16,17)}$ The processus vaginalis normally remains patent in $60-70 \%$ of infants in 


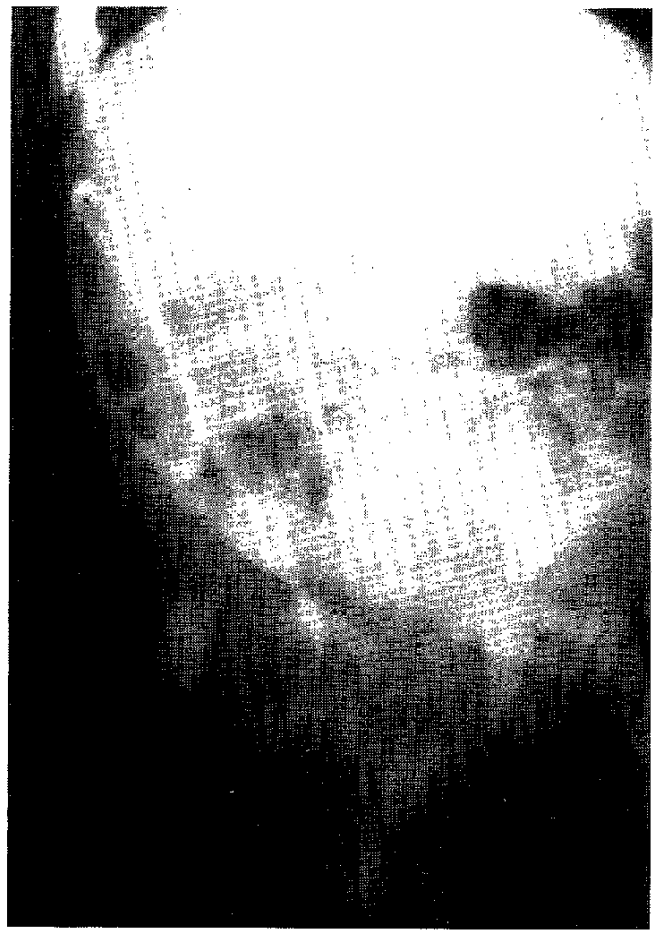

Fig. 1 Radiograph showing the shunt tip has entered the right scrotum.

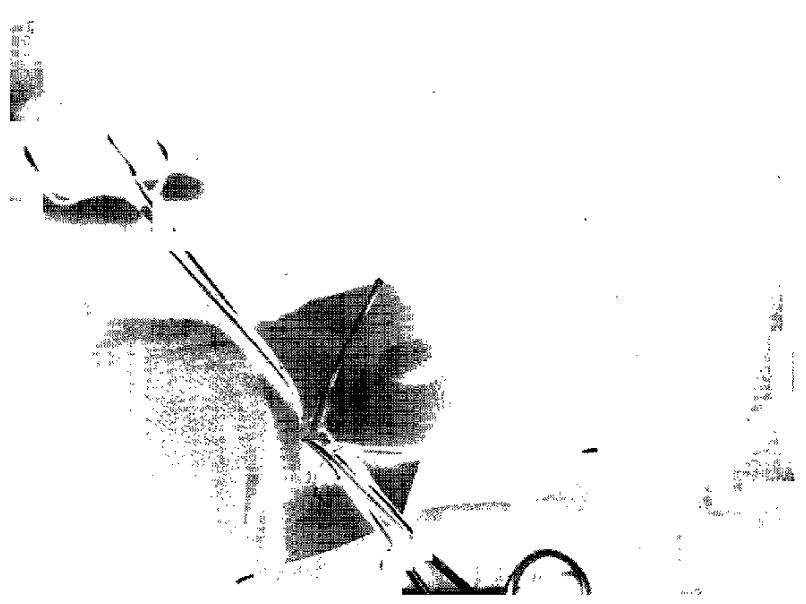

Fig. 2 Intraoperative photograph showing removal of the catheter tip from the inguinal canal.

the first 3 months of life, in $50-60 \%$ at age 1 year, and in $40 \%$ at age 2 years. ${ }^{\text {9) }}$ Patency persists in about $40 \%$ of individuals from the age of 2 years through 16 years. Adults have a patency rate of $15-30 \%$ at necropsy. ${ }^{18)}$ Our patient was in the first 3 months of life.

Two of 53 children who had received a VP shunt eventually developed hydroceles as a late complica- tion. ${ }^{13)}$ Four similar cases occurred over a 9-year period. ${ }^{4]}$ The average interval in another series between the placement of a VP shunt to the development of clinically evident hernia or hydrocele was 6.8 months. ${ }^{91}$ The interval was 24 hours in our patient.

Explanation of the migration of the peritoneal catheter is difficult but there are several possible mechanisms. Dissection of the catheter may be due to a too tight ligature stitch at the connector, or bowel contraction and repeated traction of the peritoneal catheter. ${ }^{7]}$ Chronic catheter irritation and fluid flow from the tubing may be responsible for the scrotal swelling and erythema. ${ }^{21}$ The processus vaginalis is patent in $50 \%$ to $60 \%$ of children under one year of age, so increased abdominal pressure due to cerebrospinal fluid infusion in the peritoneal cavity through the shunt system may prevent obliteration of the processus vaginalis. ${ }^{18)}$ Sustained hydrostatic intraperitoneal pressure is also observed in patients undergoing continuous ambulatory peritoneal dialysis. ${ }^{199}$ The incidence of abdominal hernias is $24 \%$, more than half of which $(16.8 \%)$ were inguinal hernias. ${ }^{19)}$ The repair of a large myelomeningocele defect may be another factor increasing intra-abdominal pressure besides the hydrocephalus. In one series, $50 \%$ of the patients had associated myelomeningocele. ${ }^{10)}$ Other cases have been associated with myelomeningocele repair and intra-abdominal complications. ${ }^{15,21)}$ We think that the migration of the peritoneal catheter into the scrotum in our patient was due to a patent processus vaginalis, and repair of the large myelomeningocele defect may have had an additional effect on increased intra-abdominal pressure.

Prompt operation following the diagnosis of inguinal hernia is advised because of the increased risk of incarceration in infancy and a higher complication rate related to operations in incarcerated patients compared to an elective procedure. ${ }^{18)}$ Contralateral groin exploration seems advisable in infants with VP shunt because of the presence of excess cerebrospinal fluid in the abdomen, likelihood of patent processus vaginalis in infancy, and the high bilaterality rate $(75-80 \%) .{ }^{9)}$

The development of scrotal swelling or hydrocele in a child with a VP shunt should be recognized as a possible shunt complication in the early postoperative period.

\section{References}

1) Alexander SR, Tank ES: Surgical aspects of continuous ambulatory peritoneal dialysis in infants, children and adolescents. J Urol 127: 501-504, 1982 
2) Bristow DL, Buntain WL, James HL: Ventriculoperitoneal (VP) shunt migration causing an acute scrotum: a case report of Doppler evaluation. $J$ Pedictr Surg 13: 538-539, 1978

3) Carbonin G: Migration of subdural atrial shunt catheter into the pulmonary arteries. J Neurosurg 52: 106-108, 1980

4) Crofford MJ, Balsam D: Scrotal migration of ventriculoperitoneal shunts. AJR Am J Roentgenol 141: 369-371, 1983

5) Ergüngör MF: Migration of an entire one-piece ventriculoperitoneal shunt into the ventricle. Turkish Neurosurgery 1: 47-48, 1990

6) Fukamachi A, Wada H, Toyoda O, Wakao T, Kawafuchi J: Migration or extrusion of shunt catheters. Acta Neurochir (Wien) 64: 159-166, 1982

7) Fuwa I, Matsukado Y, Itoyama Y, Yokota A: Migration of a dissected peritoneal shunt catheter into the scrotum. Brain Dev 6: 336-338, 1984

8) Göçer Aİ, Bağdatoğlu $\mathrm{H}$, Çetinalp E, Uzuneyüpoğlu E, Karadayı A: An unusual complication of the ventriculo-peritoneal shunt: migration of the distal end into the scrotum through the inguinal canal. Turkish Neurosurgery 1: 176-177, 1990

9) Grosfeld JL, Cooney DR: Inguinal hernia after ventriculoperitoneal shunt for hydrocephalus. J Pediatr Surg 9: 311-315, 1974

10) Grosfeld JL, Cooney DR, Smith J, Campbell RL: Intra-abdominal complications following ventriculoperitoneal shunt procedures. Pediatrics 4: 791-796, 1974

11) Levy SH, Cooper P, Shiffman D: Simulated testicular torsion in a neonate: complication of ventriculoperitoneal shunt. Urology 9: 174-176, 1977

12) Mori K, Yamashita J, Handa H: "Missing Tube" of peritoneal shunt: migration of the whole system into the ventricle. Surg Neurol 4: 57-59, 1975

13) Murtagh F, Lehman R: Peritoneal shunts in the management of hydrocephalus. JAMA 202: 98-102,
1967

14) Öktem IS, Akdemir H, Koç K, Menkü A, Tucer B, Selçuklu A, Turan C: Migration of abdominal catheter of ventriculoperitoneal shunt into the scrotum. Acta Neurochir (Wien) 140: 167-170, 1998

15) Patel CD, Matloub H: Vaginal perforation as a complication of ventriculoperitoneal shunt. J Neurosurg 38: 761-762, 1973

16) Ramani PS: Extrusion of abdominal catheter of ventriculoperitoneal shunt into the scrotum. J Neurosurg 40: $772-773,1974$

17) Redman JF, Seibert JJ: Abdominal and genitourinary complications following ventriculoperitoneal shunts. J Urol 119: 295-297, 1977

18) Rowe M, Copelson LW, Clatworthy HW: The patent processus vaginalis and inguinal hernia. J Pediatr Surg 4: 102-107, 1969

19) Rubin J, Raju S, Teal N, Hellems E, Bower JD: Abdominal hernia in patients undergoing continuous ambulatory peritoneal dialysis. Arch Intern Med 142: 1453-1455, 1982

20) Selçuklu A, Paşaoğlu A, Akdemir H, Kurtsoy A, Kavuncu I: Migration of the peritoneal catheter of a ventriculoperitoneal shunt into the scrotum. Turkish Neurosurgery 2: 52-53, 1991

21) Sells CJ, Loeser JD: Peritonitis following perforation of the bowel: a rare complication of a ventriculoperitoneal shunt. J Pediatr 83: 823-824, 1973

22) Wakai S: Extrusion of a peritoneal catheter through the abdominal wall in an infant. $J$ Neurosurg 57: 148-149, 1982

23) Wilson CB, Bertan V: Perforation of the bowel complicating peritoneal shunt for hydrocephalus: report of two cases. Am Surg 32: 601-603, 1966

Address reprint requests to: I. M. Ziyal, M.D., Susam sk. Yuvam Ap. No:20/4, Cihangir/İstanbul-Turkey. 